\title{
The Role of Law in Public Health
}

ALANSON W. WILLCOX, LL.B.

$\mathrm{T}$ O DEFINE the role of law in furthering the public health would be almost as large an undertaking as defining the role of law in the whole of our society.

The public health is to the population at large what individual health is to each of its members, a powerful force in shaping his life for better or for worse. Conceived positively as "a state of complete physical, mental and social wellbeing," to borrow the words of the WHO constitution, health becomes synonymous with human existence at its best. In the sense of enabling each man to exercise his faculties at the highest level which his natural endowment makes possible, this is a just description. In this sense the boundaries of the public health are really co-terminous with the boundaries of life.

It is one thing to describe a goal in all-encompassing terms and it is quite another to assign the workaday tasks that may lead us toward that goal. The WHO definition tells us nothing about how we are to get on with the job. But it does suggest that health is an infinitely complex affair, and that we cannot do what needs to be done without calling upon a great many skills in addition to those supplied by the health professions themselves. It reminds us that we must look at the whole man and his whole enviromment. 'This is more easily preached than it is practiced, however, for each of us, a specialist in greater or less degree, has difficulty in seeing the whole with the same clarity with which he observes his chosen part. We must therefore find ways to interrelate the many disciplines involved if we are to aroid fragmentation of our effort as a consequence of the necessary fragmentation of our knowledge.

Mr. Willcox is general counsel of the Department of Health, Education, and Welfare.
A wider and wider range of specialized knowledge of the physical and biological world has formed the base for the advances of medical science, knowledge which increasingly lies beyond the ken of the medical profession as such. But the promotion of health, in the broad sense of the WHO definition, demands an equally wide and varied interplay with skills outside the realm of physical science. And here the problems of producing effective teamwork may be even more difficult. How, for example, and under whose leadership, are we best to blend the skills of the social worker with the skills of the physician in ministering to those persons who are both indigent and ill? The health worker tends to see this as a problem of disease, the social worker as a problem of economic and social disorder. Each view is right and each is incomplete, and the solution does not lie in putting the two views in competition. Or consider the organization of metropolitan planning, in which health has so large a stake, but there are so many other stakes as well; or the methods of arriving at an appropriate balance between the boon of atomic energy and the dangers that it poses to the future of mankind. One could multiply these examples over and over again.

Of all the professions with which health workers must deal, the law is undoubtedly the most pervasive. The law not only constitutes the structural framework of the whole of our organized society including our multitude of governments, but it provides those rules or norms of conduct to which society expects adherence and the means of compelling adherence when that is necessary. Every governmental agency is created and its authority defined by law, and every administrative regulation and every expenditure of public funds must be authorized by law. Practitioners are licensed and institutions chartered and their authority fixed 
by law. Health agencies, public and private, and practicing members of the health professions, because of the critical importance to the public of what they do, are held to a high measure of accountability, of which the law is and must be the final arbiter.

The law is in some sense the master and in some sense the servant of the health professions, whether in the traditional realms of public health or in the private practice of these professions. If it is the master in defining what may legally be done and how, it should be the servant in its readiness to adapt, at the behest of other disciplines, to the changing needs of the times. If it is the servant in enforcing those rules of conduct which the health professions have found necessary to the protection of the public, it is the master in setting bounds beyond which the rules may not impinge on the rights of individuals.

We live in an age when man is challenged as never before by the need to adjust his social institutions including, conspicuously, the law to keep pace with his ever broadening mastery over nature. As Chief Judge Bazelon (1) said recently :

Although the law is preeminently the area of formal social structure, the need of the law to advance in concert with other disciplines is, perhaps paradoxically, even more urgent. Most intellectual disciplines properly proceed at their own pace; but the law, being the final repository of social decisions, must especially respond to the offerings of all others, at whatever pace proffered.

One of the chief concerns of this University of California APHA Institute on Public Health Law, it seems to me, is to consider how the law can best respond to the offerings of the health disciplines and how the pace of its response can be made adequate to the needs of the day. There will always be resistance to change, often vigorous resistance. Compulsory vaccination and the fluoridation of water offer examples from the past and the present, and resistance will assuredly increase in the future as the impact of health measures on economic and personal interests becomes sharper. But the first necessity, if Judge Bazelon's precept is to be put into practice, is to know in what direction and how far and how fast change ought to proceed. This, I think, is primarily the function of the professions at this institute, and I hope that before we disperse we shall be a little wiser in the techniques of working together to this end.

In considering the capacity of the law for change, it is worth reminding ourselves how diverse are the sources of the law and thus how numerous the points where change may be effected. Each of the three levels of government, Federal, State, and local, is the maker and the custodian of an important part of the law dealing with health and with all the other things that bear on health. At each of the three levels, legislators and judges and administrators share in the creative processes of the law, while underlying and limiting what all of them may do are the constitutions of the Nation and the States enjoining government in its entirety against undue encroachment on the freedom of the individual. And to fill the interstices in all of this we still fall back on the common law, which, though it reflects the accumulated judicial wisdom (or sometimes unwisdom) of the centuries, is yet subject not only to the will of legislatures but also to evolutionary change, and occasionally to upheaval, by the courts themselves.

Such joint offerings as our professions may produce to strengthen the law for our purposes we may have to tender at any time to a legislative committee, or in discussion with some administrator, or in a brief to a court. At times the choice of forum-Federal or State or local, legislative or administrative or judicial-may be in our hands and may bear heavily on our chance of success. But the essential interplay of law and the health sciences is not greatly different whatever the forum, and if we can find suitable ways to pool our intellectual resources it will not be difficult to adapt the product to fit whatever occasion may call for its use.

If I stress the evolution of the law I am not overlooking the need to know what the law is today, but I do want to suggest that far less of the law is static than laymen are apt to suppose. Most of the useful law, statutory as well as judicial, in the areas of concern to this institute is couched in terms broad enough to give some play in its application to the changing course of events. Since what the law is means what some judge will decide that it is, legal opinion inevitably partakes of prophecy. Where the judge's choice is not wholly foreclosed by text 
or by precedent, as it usually is not, the law of today merges imperceptibly into the law of tomorrow.

Some of my friends of the bar will accuse me of undermining their authority by implying that the law can have no certainty at all. This I do not mean to imply. Legal diagnosis is rather like medical diagnosis. In most cases encountered from day to day, the result is predictable enough to afford a sound basis for practical courses of action. But surprisingly often-and especially, it seems to me, on matters of large public import-the lawyer's task is an appraisal of the probabilities. And in these cases, where real choice is open to a court, the same factors that will shape our judgment of what the law ought to be in the future are pertinent to a judgment of what the law is today.

The significance of these considerations for this institute I think is plain. We need to be in communication with each other, not merely on those rare occasions when some bold new plan is in the making but day in and day out in all that we do. The administrator who wants sound legal advice in his ongoing program had better attend to his lawyer's education in everything that has to do with health, and he had better be a receptive pupil at the same time that he is a teacher. Let me illustrate.

When your lawyer is asked about the legality of administering an experimental drug to an incompetent patient and what explanation of risk should be made to whom-a problem on which judicial precedents afford not very particular guidance-his advice will be meaningful in proportion as he understands the full significance of the choice that is before you. But while you are explaining to him its medical significance and why the drug is medically indicated, you will be learning something of the legal principles by which it would be judged if the case should go to court, and you also will be sharpening your own analysis of the problemoccasionally, perhaps, modifying your original conclusion. Once you and he have reached agreement, the chances are strong that he could convince a judge if occasion should arise-which is another way of saying that at that point you have good legal advice.

The program of this institute suggests the dimensions and diversity of the role of law in the problems of health that we are cognizant of today. But as President Kennedy remarked not long ago-whenever science comes up with a major new discovery, we have to devise new institutions to deal with it. Since the law must create and be a part of these new institutions, an institute's program can only be a cross section, in time, of relationships that are likely to change their contours markedly in the years ahead.

One part of this program, I am glad to note, is devoted to legal problems in medical care, in hospital administration, and in the provision of organized health services. Whatever contributes to the public health, under whatever auspices carried on, is appropriate to our discussion. The more so because the private sector of the health economy includes important points at which the relationship with the law has been less than satisfactory, and to which there is clear need to bend the joint effort of our professions.

Apart from the matter of professional liability, we need not concern ourselves greatly with the solo practitioner. Much of the practice of medicine, however, and of other of the healing arts can be carried on today only in an institutional setting, and it is reasonable to suppose that pressures in this direction will increase as the complexity of medical procedures grows and their costs continue to mount.

The law has undoubtedly been laggard in supporting the institutional mechanisms for medical practice that have already developed and is in need of important rethinking. Perhaps we can even do a little to prepare for the demands of the future, at least by making the law more flexible and thus easier of adaptation to the new ideas that will have to emerge.

The modern hospital, which is the most prevalent example of institutional medicine at present, is to a real degree an administrative and legal anomaly. As an abstract question, who, in designing a service organization of utmost complexity, would suggest entrusting the central core of its service to independent entrepreneurs whose relation to its governing body is tenuous and whose allegiance to the institution is measured by their collective or even their individual sense of professional responsibility? Who, if we were starting from scratch, would 
view the typical hospital of today as a charitable organization created to dispense its benefits to the poor?

If the modern hospital, despite these anomalies, can nevertheless function effectively - as it unquestionably can in providing the inpatient care for which it was brought into being-we owe its success largely to the devotion of the members of its medical staff who give untold hours of their time, without monetary compensation, to the work of staff committees. In many institutions this loose organization, improbable though it seems, is quite effective in knitting together a group of otherwise autonomous practitioners. Even the division of responsibility, between the hospital and the physician, for the patient's welfare has proved much less hazardous in practice than it seems in theory. Meanwhile, the continuing education of the practicing profession, with all that it means to the quality of medical care, owes a great deal to these medical staff committees and to the surveillance of each other's work that physicians accept in the hospital environment as most of them accept it nowhere else. As long as these things are true, who are we to cavil?

Perhaps much the same thing can be said of the legal anomaly that treats community hospitals essentially as charitable institutions. Taxwise, as long as the myth is respected, no great harm is done to the hospitals, although its mythological base has impeded the extension of the tax immunity to other and equally deserving medical institutions. In some States the myth still shields these hospitals from responsibility for carelessness, but more and more courts have corrected this historical aberration. Although it would be intellectually satisfying to treat hospitals for what they are, we have more serious business before us than reversing harmless error.

Even in the care of inpatients, the conventional organization of hospitals poses many problems that concern both the medical and legal professions and could profit from further study carried on in concert. I will confine myself to two points at which, to my way of thinking, the law has been too ready to support certain parochialisms that exist within the medical profession, and to do so without adequate attention to the interests of the public.
The first has to do with the centrifugal force exerted by specialty groups in the organization of major hospital functions, notably their laboratory and radiology departments. A large measure of autonomy is demanded for these units by the respective associations of specialists, in the name both of professional ethics and of the law, and the demand extends to the large and lucrative volume of work done in these departments by laymen. In my judgment neither ethics nor law warrants the specialists' demands, but there are States in which the law limits, and many in which it beclouds, the range of choice that is open. What seems altogether wrong in theory may be acceptable in practice, but surely a governing board should be free, if it deems this course in the interest of its patients, to operate these essential hospital services through salaried employees, professional as well as lay.

The other point I would make is that in one respect I believe the law has been too lenient. The conventional view has been that a nongovernmental hospital, like a private club, may, except as its own bylaws forbid, be as arbitrary as it wishes in granting or withholding the privilege of staff membership. Some of us have suspected that this statement of the law was an oversimplification, and our suspicions gained support when the Supreme Court of New Jersey rejected the conventional view at suit of a fully licensed osteopath (2), and more recently, when a Federal court of appeals decided that avowedly discriminatory Hill-Burton hospitals must consider applications by Negro physicians (.3). These decisions should cause courts elsewhere to reexamine their premises. The interests at stake are too great and the hospital is too deeply committed to public service to permit so narrow a rule to be accepted as the final word. If hospital medical staffs want to keep control of the quality of their membership-and unless we can find a better scheme, it is altogether essential that they should-it behooves them to desist from discrimination, whether on the ground of race or religion or medical politics or mere social acceptability.

When we turn to outpatient care, the organization of the modern hospital has produced results rather less satisfactory, and prospects for much improvement are not immediately hopeful. 
The first necessity, if hospital centered or other group practice is the direction in which we should move, is to devise patterns that will appeal on their merits to a larger segment of the practicing profession. Many of the best, I am convinced, are deterred not only, and perhaps not primarily, by economic fears but by concern-whether well or ill founded is beside the point-lest professional excellence be endangered. Here legal problems are important but secondary. We must devise mechanisms, as the hospitals have done over a long period of time, which will satisfy the skilled and dedicated members of the profession-not an occasional adventurous soul but the great numbers of physicians-that their ability to perform at their highest capacity will not be diluted by submergence in a group. Once ways are found to satisfy this requirement, the road will be opened to changes to which the law will adapt itself, if only because it must. But until there is a greater consensus within the medical profession I do not believe we can do more than help to clear away some of the existing legal underbrush.

The matters I have been talking about, and many like them, concern public health officers not so much because of anything written on the statute books as because health officers are or should be, by virtue of their office, advisers to their Governors and their legislatures in all that pertains to health. It is a part of their job, I suggest, to establish their position as spokesmen when issues that bear on health are being debated anywhere in government.

The rest of the program of this institute deals with problems of environmental health and sanitation, which are of course the direct and official responsibility of public health officers and their legal advisers. These are problems of high priority, and they serve well to illustrate, though they by no means exhaust, the range of useful interplay between our professions in discharging the accepted health responsibilities of government. The law is a component of almost all that health agencies do including everything that goes beyond education and persuasion. Where law is a component of action, legal thinking should be a component of policy formulation and decision. This means that every State health agency should have full- time legal service, and that local agencies should at the least have ready access to advice from lawyers who are thoroughly familiar with both the policies and the problems of the agencies.

When public agencies give health service to individual members of the public they face most of the same legal questions that private agencies face, but the subtle problems incident to involuntary hospitalization for mental illness are in the main peculiar to public institutions. How do we minimize trauma to the patient while protecting his civil rights? Here, thanks to intensive interdisciplinary discussions, we have made in the last decade or so great progress toward agreement on guiding principles. But much remains to be done to translate these principles into practice-legislatures to be moved into action where antiquated procedures still prevail; differences of opinion on particulars to be ironed out; new community mental health centers to be established and their role defined; mechanisms to be devised to lessen the risk that senile or other long-term patients may be lost or forgotten in our huge State mental institutions.

Much remains to be done, also, to bring the law in all its aspects into better harmony with current understanding of mental illness and mental retardation. Under what circumstances are the victims of these afflictions competent to manage their business affairs, to marry, to drive a car? Apart from compulsory hospitalization, what forms of custodianship of their persons and guardianship of their property will best serve their needs? The Public Health Service has recently made grants for comprehensive planning in the field of mental illness and will soon be making similar grants with respect to mental retardation-planning which, in either field, requires the concerted effort of health officers and lawyers and many others.

I shall not venture into the thickets of jurisdictional argument in these or other matters. I shall not suggest whether health service to the needy, for example, or the regulation of food and drugs belongs in health agencies or elsewhere in State and local government. Plainly, health officers should be involved in one capacity or another in programs that so directly bear on health. And even where their role is secondary or wholly advisory, I believe that their 
lawyers can often be of help in presenting effectively, in whatever forum may be appropriate, the views of the health professionals.

Environmental health is a happy choice for the program of this institute. For one thing it illustrates, as well as any part of public health responsibility, the need for a close and constant interplay between our professions, whether it be in the framing of a statute or regulation or ordinance or in projecting a program of enforcement or in bringing some individual offender to book. Then too, it is a field in which the law is emphatically still in the making; in the early stages of making, I would say, in view of the huge complexity of the problems we already face and the certainty that they will grow all too fast in the years ahead.

Two aspects stand out as posing an extraordinarily difficult challenge to effective governmental action. The first is the huge vested interest which we have allowed to accumulate already in the pollution of our environment and the danger that new interests in pollution will vest more rapidly than we can devise protective measures to head them off. The other aspect is the difficulty of enforcement against a multitude of small wrongdoers where no single wrong is large enough to be serious in itself but in aggregate is a threat to the health and welfare of us all.

Here the law must be an integral part of longrange as well as short-range plans and of the thought and study that must lead us toward them. Since law will continue to be the instrument through which regulation is brought to bear on those who must conform, legal methodology will have to develop hand in hand with scientific methodology. New techniques for the control of pollution, however appealing to the engineer or the chemist, will be effective in proportion as the law can devise techniques for enforcement that will be within the bounds of constitutional power and also within the capacity of our legal system. Here is a joint enterprise worthy of the best that we can give.

I have tried to suggest how nearly limitless is the ground common to the health professions and the law, and how important it is that we not parcel out this ground for separate ownership but share the whole of it in joint tenancy. Perhaps I can point the moral by contrasting the present state of affairs, which I have already noted, in two sections of our common territory.

About a dozen years ago, at the instance of the National Advisory Mental Health Council, a group of psychiatrists and lawyers in the Federal Security Agency undertook the task of framing a draft law for the hospitalization of the mentally ill. Over a period of many months these people met together and with outside authorities and gradually hammered out the issues and acceptable solutions. It was a process not essentially of compromising differences but rather of enabling each profession to understand and absorb the point of view of the other, and thus of producing in the end a measure substantially agreed upon by a group that had started out with considerable divergence of opinion between the participating professions. The model this group developed has been improved and refined as a result of later work both within our Department and elsewhere, and there is available today, to any legislature that can be induced to consider it, draft legislation that should attract wide interdisciplinary support and should give the legislature a good start in bringing outmoded law up to date.

Contrast with this the history of the corporate-practice rule which, though created for good purpose to end certain truly shoddy practices, was framed with apparently no awareness at all of its impact on institutions which form the backbone of our system of caring for health. Because lawyers saw a solution to an immediate problem, they induced courts to pronounce a rule which is so wholly at odds with reality that no one has ever proposed to enforce it across the board. A few courts, be it said, were wise enough to avoid this pitfall at the start, and several others have worked their laborious way back to a rule of commonsense. But all of this was quite unnecessary. All that was needed was a little understanding, on the part of a few lawyers and a few judges, of certain medical facts of life. As things happened, however, a rule developed that is not only an obstacle in many States to new and desirable forms of medical practice but is also a continuing threat to highly reputable institutions of the most impeccable orthodoxy. 
If mishaps such as this are to be avoided in the future and, more importantly, if we are to join our efforts effectively to meet the necessary challenges of today and tomorrow, we must pursue all of the paths that may lead to better communication between our professions and better understanding, by each, of the principles that guide the other. Certainly one of the first needs is to strengthen the lines of communication between us at the working level for all the State and local officials whose day-to-day responsibilities cut across the boundaries of our professions.

Institutes such as this, although they can be no substitute for proper working relationships in the course of administration, can provide a stimulus as well as a supplement to such relationships. I am sure that a lawyer assigned to a public health agency, participating in discussions like those at this institute, will return to his job with a new determination to understand all the implications of the issues that come before him. And I do not doubt that the public health officer will profit in much the same way. If an institute accomplished nothing but this-if it merely drove home the lesson that a proper relationship between administrators and lawyers cannot be built of paperwork alone-it would be well worth the effort.

The informality and the oral discussion that are so essential to mutual understanding are not always easy to arrange. Organizational separation, as when the lawyers are members of the attorney general's staff, may but need not be an obstacle. The chief tangible desiderata, perhaps, are full-time legal service and physical proximity of lawyers to administrators. But though the objective seems plain enough, the human equation enters largely into these relationships and the human equation contains too many variables to permit of standardized solution.

Other paths that we need to explore lead further into the future. It may be, for example, that some modification of the formal educational processes would enable public health workers and lawyers to enter upon their careers with a little more knowledge of the interplay of their professions.

You have under consideration, I am told, the creation of a health law center here in Cali- fornia, and I hope that you will find it possible to proceed. Through publications, through interchange with health officials and their lawyers, through fostering and participating in health law institutes, such a center can contribute to the continuing education of all of us concerned with the public health. Through research it can add to the sum total of our knowledge and to our readiness to cope with the present and the future.

Our concern for the public health, pitted as it must be against the unplanned consequences of free enterprise in a technologically explosive world, calls for a continuous play of imagination unbounded by the dogmas or even by the hypotheses of any one profession. Yet if we are to avail ourselves of what wisdom we have, the learning of each profession must not be overridden in the process of adapting it to our common ends. Basically, our task is to mold the thinking of the several groups into parts of a larger whole.

There are many techniques by which we seek to relate the expertise of the specialist to problems that transcend the boundaries of his specialty. There are many paths that may lead our professions toward composite judgments more embracing than the sum of our partial or particular points of view. We shall be testing here one method of effecting the necessary interdisciplinary communication. But let us bear in mind that this institute can be only a beginning, and that there are matters of our common concern that call for joint study in greater depth than we can give them in so brief a time. While we are taking this step it is none too soon to be planning for the other steps that must follow.

\section{REFERENCES}

(1) Bazelon, D. I. : Foreword. In Report of the Task Force on Law to the President's Panel on Mental Retardation. U.S. Government Printing Office, Washington, D.C., 1963.

(2) Greisman v. Newcomb Hospital, 40 N.J. 389, 192 A. 2 d 817 (1963). Cf. Falcone v. Middlesen County Medical Society, 34 N.J. 582, 170 A. 2d 791 (1961); Willis v. Santa Ana Community Hospital Association, 58 Cal. 2d 806, 376 P. 2d 568 (1962).

(3) Simkins v. Moses H. Cone Memorial Hospital, 323 F. 2d 959 (Ct. App., Cir. 4, Nov. 1, 1963 ; certiorari denied Mar. 2, 1964). 